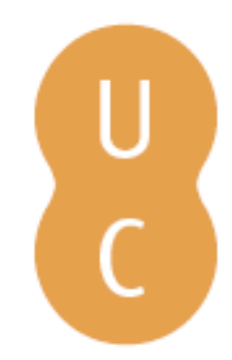

\title{
pommalina
}

As representações da música na arte portuguesa: contributo para um banco de dados iconográfico

Autor(es): $\quad$ Amorim, Maria Adelina; Serrão, Vitor

Publicado por: Imprensa da Universidade de Coimbra

URL

persistente: URI:http://hdl.handle.net/10316.2/30039

DOI: $\quad$ DOI:http://dx.doi.org/10.14195/978-989-26-0567-8_9

Accessed : $\quad$ 26-Apr-2023 03:24:42

A navegação consulta e descarregamento dos títulos inseridos nas Bibliotecas Digitais UC Digitalis, UC Pombalina e UC Impactum, pressupõem a aceitação plena e sem reservas dos Termos e Condições de Uso destas Bibliotecas Digitais, disponíveis em https://digitalis.uc.pt/pt-pt/termos.

Conforme exposto nos referidos Termos e Condições de Uso, o descarregamento de títulos de acesso restrito requer uma licença válida de autorização devendo o utilizador aceder ao(s) documento(s) a partir de um endereço de IP da instituição detentora da supramencionada licença.

Ao utilizador é apenas permitido o descarregamento para uso pessoal, pelo que o emprego do(s) título(s) descarregado(s) para outro fim, designadamente comercial, carece de autorização do respetivo autor ou editor da obra.

Na medida em que todas as obras da UC Digitalis se encontram protegidas pelo Código do Direito de Autor e Direitos Conexos e demais legislação aplicável, toda a cópia, parcial ou total, deste documento, nos casos em que é legalmente admitida, deverá conter ou fazer-se acompanhar por este aviso.

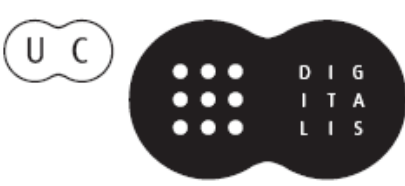




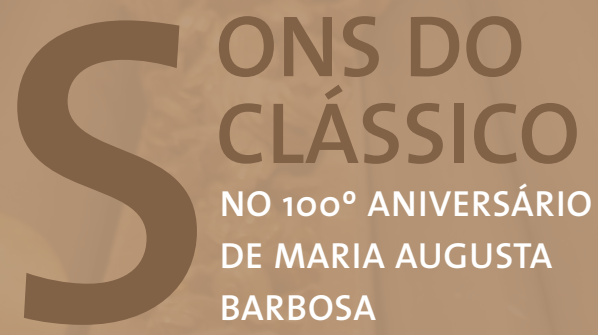

J. M. Pedrosa Cardoso

Margarida Lopes de Miranda COORDENAÇÃO 
Maria Adelina Amorim ${ }^{57}$

Associação de Cultura Lusófona - Universidade de Lisboa

Vitor Serrão ${ }^{58}$

Instituto de História de Arte - Universidade de Lisboa

\section{AS REPRESENTAÇÕES DA MÚSICA NA ARTE PORTUGUESA: CONTRIBUTOS PARA UM BANCO DE DADOS ICONOGRÁFICO}

\section{Sensibilização para um problema de património artístico nacional}

Desde muito cedo, tanto na sua produção científica como na sua actividade de docência, a Prof. Maria Augusta Barbosa (n. 1912) sentiu quão importante era o património artístico português no que toca às representações musicais e pôs a tónica na necessidade de se desenvolverem mais e melhores estudos que permitissem dar a conhecer esses acervos, quer no território continental, quer nos interfaces da presença portuguesa no mundo.

$\mathrm{Na}$ realidade, percorrendo os livros de arte, os catálogos de grandes exposições, os inventários artísticos (como o da Academia Nacional de Belas Artes

57 M.A.A. - Presidente da Associação de Cultura Lusófona da Universidade de Lisboa. Aluna da Prof. Maria Augusta Barbosa, quer durante a licenciatura em História, quer no Mestrado em História e Cultura do Brasil, em que a Querida Mestre leccionou a cadeira e o seminário de História da Música e História da Música no Brasil Colonial, respectivamente, vem deixar um preito de homenagem verdadeira e sentida a uma das pessoas maiores que encontrou no seu percurso académico e pessoal, a que ficou ligada por profundos laços de Amizade, que tornaram os cerca de vinte e cinco anos de convívio pessoal e quase quotidiano, um tempo profícuo de aprendizagem de Vida, de rectidão, de carácter, de profissionalismo, de dedicação às Artes e ao Saber, sendo ao mesmo tempo portadora de uma Humildade que só os Grandes Mestres possuem, e só os Iluminados cultivam. Maria Augusta Barbosa é indubitavelmente, as duas coisas. A autora deixa o mais reconhecido, íntimo, profundo e eterno OBRIGADO.

58 V.S. - Professor Catedrático. Instituto de História da Arte da Faculdade de Letras da Universidade de Lisboa. Colega de Maria Augusta Barbosa durante o tempo da sua leccionação na Faculdade de Letras da Universidade de Coimbra, compartilhando quase semanalmente o mesmo comboio que os levava de Lisboa para a cidade coimbrã, onde houve oportunidade de trocar experiências, saberes e preocupações comuns pelas Artes a que têm dedicado a sua vida profissional e pessoal. 
e os das comissões de arte sacra das Dioceses), as monografias e estudos parcelares, etc etc, facilmente se verifica, pela simples observação das imagens reproduzidas, que a arte portuguesa, desde a Idade Média até à contemporaneidade, não se alheou da realidade musical, abrindo-se à representação de instrumentos musicais, de grupos de músicos e cantores e, em casos mais raros mas não menos explícitos, à alegorização da própria Música como esteio das Artes Liberais.

São milhares as representações que podem ser assinaladas: a pintura a óleo e a fresco, o azulejo, a escultura e a talha, a iluminura, a ourivesaria, o mobiliário, os têxteis, os couros lavrados e, inclusivamente, artes decorativas como os embrechados e os estuques, abriram-se à presença de temas musicais e à figuração dos seus atributos e instrumentos, multiplicando a sua figuração, do século XII até aos nossos dias, em vários materiais e suportes, consoante a evolução dos estilos, a maior ou menor capacidade de observação dos temas e a importância relativa das representações em determinados contextos iconográficos religiosos, alegóricos ou profanos.

Conforme reconheceu sempre a Prof. Maria Augusta Barbosa, na sua docência e no seu diálogo aberto com os que com ela tanto privaram, com essa sua especial sensibilidade para sentir a Música em todas as suas manifestações - eruditas e populares, europeias e extra-europeias ${ }^{59}$ - o papel das

59 Haveria muito para desenvolver a este respeito numa pesquisa dos testemunhos que deixou nas suas aulas, nos seus acompanhamentos científicos e orientações académicas ou, por exemplo, nas visitas de estudo em que acompanhava os alunos. Ficaram célebres as idas ao Palácio Convento de Mafra, onde disciplinava os estudantes a toque de uma pequena sineta que sempre a acompanhava, e em que era a primeira a chegar aos carrilhões depois de se terem percorrido quilómetros de corredores do actual Museu. Do mesmo modo, restam nas memórias dos seus alunos as visitas a Conímbriga, a Évora, aos Capuchos em Sintra (era bom ouvir o silêncio; perceber as escalas físicas e humanas, a grandiosidade da natureza, o valor do recolhimento para fruir o som, o breve bater de asas, o doce murmurar da água, o chilreio, o ferrolho, a porta velha... Tudo eram sons que nos eram transportados. Bastava ouvir. Mas nada que se comparasse a um desabar de uma violenta tempestade, sonoras, pujantes e brutais embates de nuvens carregada de som e brilho. E o mar... o mar batido, vigoroso e poderoso do Guincho, da Boca do Inferno... o vento do Cabo da Roca, a carga hierofânica do Cabo Espichel e o abrigo do Santuário de Nossa Senhora do Cabo. Tudo servia ao mesmo propósito pedagógico, tudo eram instrumentos, metodologias, quase um proselitismo para convidar os aprendizes a perceber que a Música é uma Arte Maior, universal. Dava tanta importância à mais complexa, acabada, exemplar composição e interpretação - era profundamente crítica e de um fino e inteligente humor - como a um xilofone ou a um chocalho. Impressionava-se tanto com a execução de uma renomada orquestra, como se enchia de ternura perante uma pequena escultura de madeira de um homem tocando marimba. Pegava nos instrumentos com um grau de veneração igual, fosse uma lira-apolo, uma harpa, um violoncelo, uma viola de bracio ou fosse uma banza de socopé, um mpungui, uma Koré ou um apito. Dava a mesma importância aos grandes organeiros, aos 
artes abriu-se sempre à presença da música e é por isso que impõe sempre uma disponibilidade maior de observação integral por parte dos estudos das Ciências Musicais. Seja a decoração da arquitetura clássica e medieval, a imaginária em madeira, terracota e pedra da Idade Moderna, a pintura a óleo, a têmpera e a fresco do Renascimento e do Maneirismo, o azulejo do Barroco, a paramentaria, o mobiliário, as pratas e alfaias litúrgicas, o estuque, e tantas outras componentes que século a século integraram os músicos e a música como partes essenciais da representação sacro-profana, tudo no campo das artes impõe um olhar atento, não formalista e não meramente histórico-documental, pois esse campo tem em si valências de longo curso.

A metodologia da História da Arte não se esgota, como bem se sabe, na via da investigação dos arquivos, ou na via da análise laboratorial de peças, mas impõe sempre o estudo estilístico e comparativo, iconográfico e iconológico das obras de arte (de todas as obras de arte) de per si. Um inventário exaustivo das representações musicais só faz sentido, nas suas palavras, se integrado numa visão globalizante, em que não é só a peça que conta, e o modo como o instrumento foi tratado pelo autor, mas as razões que o levaram a fazê-lo no contexto de uma encomenda precisa e com públicos bem definidos.

No âmbito de uma disciplina científica como é a História crítica da Arte, que visa, à luz dos seus próprios conceitos e modos de fazer, dar a conhecer melhor as obras de arte, estimular o ato da suas leitura na sua componente de integralidade, saber avaliá-las como produtos específicos de conjunturas, épocas e situações do tempo histórico (e além do tempo histórico), é tarefa dos estudiosos que a pratiquem saber situá-las em contexto, entendê-las como objectos vivos dotados de fascínio duradoiro e como testemunhos estéticos dotados de carga trans-memorial, a fim de poder justamente unir, tanto quanto for possível, as componentes do gestor das artes com a do historiador-crítico

mestres fabricadores dos mais preciosos violinos, como levava os alunos à oficina do artesão bracarense Domingos Machado onde ficavam horas a observar a mestria das sua mãos na fabricação manual da violas típicas como a Campaniça Alentejana, a Beiroa, a Braguesa, a da Terra a da Madeira, a Toeira de Coimbra, etc. Do mesmo artista saíam guitarras, bandoliras, banjolins, banjos, bandolas, bandolocelos ou cavaquinhos de Lisboa ou do Brasil... Tudo era apresentado com o mesmo grau de rigor, tudo era elevado ao grau de obra-prima, desde que o artesão. Mestre, artista, músico, intérprete, compositor fizessem a sua arte com os sentidos e o apuramento que depois a técnica e a prática e a disciplina treinavam e aperfeiçoavam. 
e com a do connoisseur de obras artísticas, sem esquecer que muitas dessas peças são, também, objetos de culto e, por isso, mantêm incólume as suas dimensões de intermediários de fé, não deixando por isso de ser também e sempre obras de arte.

Estudar-se a música no contexto da sua representação em obras do Património artístico nacional impõe sempre o reconhecimento destas vertentes.

\section{Dimensões da Música na e com as obras de arte}

A dimensão trans-contextual dessa música eternizada na pedra, na madeira ou no barro pelo escopro e pincel dos artistas apresenta-se, fascinante, nas muitas pinturas das Assunções da Virgem pintadas pelas oficinas portuguesas do século XVI.

O tema exaltava o triunfo da fé e, por isso, a presença dos anjos músicos era um imperativo da iconografia. Uma tábua quinhentista como a da igreja matriz de Sardoura (Lamego), por exemplo, estudada pelo musicólogo Mário de Sampayo Ribeiro nos anos quarenta do século passado com toda a atenção, num ensaio pioneiro sobre as representações musicais na nossa pintura antiga, veio demonstrar esse cuidado extremo da representação, com a sua dimensão contemporânea muito acentuada, mas revelou, também, que em muitos dos casos se revelam distintas atitudes dos artistas face ao verismo das peças observadas (neste caso a da igreja de Sardoura, onde os anjos tocam charamelas, sacabuxa e órgão portátil, ressoando uma espécie de sinfonia que envolve a Virgem Maria, acima do túmulo e dos Apóstolos assistentes). ${ }^{60}$

Mas nem sempre as representações religiosas na pintura, mesmo quando aparentemente cuidadas no seu aspecto funcional, revelam um conhecimento das fontes, e apenas e só uma derivação de modelos (por via de gravuras ou por via do conhecimento de outras obras) - e esse é um aspecto absolutamente a considerar nos nossos estudos. ${ }^{61}$

\footnotetext{
60 M. de S. Ribeiro 1943

${ }^{61}$ Idem, op. cit.
} 
Mas não haja dúvidas que é notável a quantidade e diversidade de instrumentos que se apresentam nos retábulos de culto e nos frescos pintados do século xvi (mais do que alguma outra época), tanto da chamada música baixa como da música alta, num exercício de conjugação entre erudição e populismo, entre festa cortesã e rural, entre dimensão profana e espiritual. Vemos aí representados, entre santos de altar ou no contexto de milagres e de cenas do hagiológio cristão, moços de câmara e anjos, jograis e bailadeiras, pastores de gaita-de-foles e menestréis, ouvimos quase o som dos alaúdes, da harpa, da rabeca, da viola de gamba, da charamela, do órgão, da guitarra, do saltério, da sanfona, das pandeiretas, dos guizos, dos tambores, dos címbalos, das trompetas e sacabuxas, etc etc, e chegamos a sentir o frémito da música que nos chega registada em pautas reconhecíveis (e reinterpretáveis), como sucede em tábuas do pintor Garcia Fernandes (no Mosteiro de Ferreirim), do famoso Vasco Fernandes, o Grão Vasco (na igreja de Aldeia Viçosa, Guarda) ${ }^{62}$, do mais modesto pintor Bastião Lopes (em Nossa Senhora de Brotas, Mora) (Fig.6) ${ }^{63}$ ou do pintor flamengo, já maneirista, Francisco de Campos (Évora), entre outros pintores quinhentistas que tiveram especiais cuidados nas representações da componente musical em cenas religiosas destinadas a grandes comunidades de devotos... E na igreja matriz de Veigas (Bragança), a capela-mor deixa ver, pintado a fresco no fim do século xvi, um tocador de alaúde em pose profana, dando uma nota de festividade popular ao presbitério, lugar central do vulto numa comunidade como essa pequena aldeia transmontana... O mesmo se passa nas orquestras ao vivo, digamos assim, em ciclos de azulejos barrocos do início do século xvıII, seja no claustro do Convento agostinho da Graça de Torres Vedras (pelo mestre P.M.P., c. 1720) ou no atual refeitório do Convento paulista da Serra d'Ossa (por António de Oliveira Bernardes, c. 1710) (Fig. 7).

Este espectáculo da música que se eterniza na representação dos artistas, tanto eruditos como populares, é perenizado ao longo dos séculos e não encontra só o acento maior na pintura do século xvi (como passou a pensar-se numa dimensão muito redutora. Quando admiramos um belíssimo painel

62 V. Serrão 2001

63 Esta tábua (Fig. 6) foi dada a conhecer por Túlio Espanca no Inventário artístico de Portugal. A atribuição ao pintor eborense Bastião (ou Sebastião) Lopes carece ainda de contraprova. 
de azulejos com um passo do Cântico dos Cânticos pintado por António de Oliveira Bernardes, cerca de 1710, num dos espaços monacais do Convento de São Paulo da Serra d' Ossa, com a sua sinfonia vibrante de instrumentos representados com detalhe de realismo, atesta-se o quanto o encanto da música e o fortalecimento da dimensão espiritual andaram sempre de mãos dadas, num exercício de encantações a que o talento dos melhores artistas deu corpo tangível. ${ }^{64} \mathrm{~A}$ arte do Azulejo português, aliás, possibilitou alternativas importantes à representação musical, já que esta modalidade teve, para além da componente religiosa que o seu uso em tempos de Contra Reforma acentuou, uma poderosa dimensão profana, cortesã, cenográfica e venatória, muito bem tratada, por exemplo, por José Meco. ${ }^{65}$

Nem sempre as representações musicais surgem como reforço legitimador ao discurso mariano e cristológico. Também contribuem para acentuar o sentido da pedagogia e a ardência da alegoria moral. Quanto vemos, no Paço de Vila Viçosa, os dois grandes tetos das Salas da Música, pintados nos anos 30 do século XVII por ordem de D. João IV (ainda Duque D. João II de Bragança), com um coerente e bem desenvolvido programa em torno dos Encantos da Música - iconografia de Orfeu, triunfo da Música Profana, alegoria à Fonte de Hipocrenes e à Música vencedora da Guerra, etc - e do Cântico dos Cânticos - triunfo da Música Sacra, história de David, Jahel e Sisara, etc -, vemos como Música e Pintura se encontram em uníssono, à luz de um programa iconológico definido ao pormenor pelo futuro rei Restaurador, em catalogação plástica e devidamente paragonada das mais-valias da Música Sacra e da Música Profana, para legitimar o peso da cultura musical na corte bragantina (Fig. 9). ${ }^{66}$ Sabemos pelas fontes de corte que D. João IV, compositor de grande talento e musicólogo de projeção internacional, gostava de ver José do Avelar Rebelo pintar, e com ele discutia Pintura - mas por certo também a Música que esse artista ia representando em alegorias no teto do salão régio de Lisboa, esse desaparecido teto da Sala de Música do Paço Real da Ribeira, em Lisboa, que o terramoto de 1755 arrasou. Rui Vieira Nery estudou bem essa obra, pintada por Avelar Rebelo a mando do seu amigo D. João IV, descrevendo à luz das

\footnotetext{
64 J. Meco 1989.

65 Cf. J. Teixeira 1983 e V. Serrão 2008. Sobre D. João IV músico, cf. R. V. Nery 1991.

66 Cf. J. Teixeira 1983 e V. Serrão 2008.
} 
fontes as suas múltiplas alusões à Música na Antiguidade, além de retratos de compositores célebres como Palestrina e os portugueses Manuel Cardoso e João Soares Rebelo, o Rebelinho. ${ }^{67}$

Sem intuitos de exaustividade, lembramos como os grandes artistas europeus encontraram muitas vezes o aliado providencial na Música para comporem as suas melhores obras. Por exemplo, o célebre bolonhês Domenico Zampieri, o Domenichino (1581-1641), é exemplo do artista pictórico musical, cujo interesse pela antiga música cromática e harmónica era tão vasto que fez construir para si um cravo e uma harpa, e projectava conseguir um órgão "com todo o tipo de atónicos, cromáticos e harmónicos" para afinar as harmonias da música com as harmonias da pintura ! O esforço com que este pintor e arquitecto concebeu a 'lira barberina', que dedicou ao Papa Urbano VIII (Maffeo Barberini), o grande pontífice da Roma seiscentista, atesta essa hipersensibilidade auditiva do pintor bolonhês, exemplo acabado de artista de múltiplos empenhos criativos e receptivos, na busca da harmonização do mundo através da Música. ${ }^{68}$ Como exemplo dessa paixão partilhada pelas duas sensibilidades da alma, Pintura e Música, restam do grande pintor bolonhês Domenico Zampieri dois "quadros musicais", La Sibila de Cumas e Santa Cecília (Galeria Borghese, Roma) que tiveram como modelo a sua própria mulher, a bela Marsilia Barbetti.

Podem juntar-se a esta galeria de pintores-músicos, que se deleitavam nos duplos prazeres dos sentidos, um Verrochio, que foi a seu tempo artífice, escultor, entalhador, pintor e músico, Fra Bartolomeo, Giorgione, Rosso Florentino ou Ticiano Vecellio, que "tocava violino e viola para esparcimiento e repouso das épicas fadigas pictóricas". O próprio Leonardo da Vinci foi virtuoso no uso da lira de braço e arco, de que deu várias provas ao lado de profissionais músicos de corte. Também Tintoretto, Guido Renni, Cellini ou Salvator Rosa foram exímios compositores e intérpretes de instrumentos. Tal virtuosismo fê-los transpor para as mãos dos anjinhos tocadores das suas telas musicais, os instrumentos cujos sons os deleitavam, e com que duplamente glorificavam o Divino e o apraziam Humano.

\footnotetext{
67 R. V. Nery 1991.

68 E. Fabiani 1993.
} 
Para terminar esta breve referência a mestres pintores, lembre-se Caravaggio, que cerca de 1594-1596, ainda muito jovem, pintou aquela que viria a ser uma das suas obras-primas, O Repouso na Fuga para o Egipto (Galeria Pamphili, Roma), onde um anjo como figura central da cena toca violino a partir de uma partitura mostrada por São José, deixando-se para um plano periférico a Senhora e o Menino que dormem placidamente ao som do instrumento. O grau de precisão e conhecimento musical era tão profundo que o grande mestre Caravaggio pinta a partitura com um grau de composição perfeito, passível de ser lida por paleógrafos musicais, e interpretada, uma vez que constitui um conjunto melódico lógico e uniforme, a par de ser uma das primeiras representações gráficas, neste caso pictórica, do violino moderno com as suas especificidades próprias. ${ }^{69}$

Também El Greco, na sua casa de Toledo, se comprazia em pintar no atelier com assistência de uma companhia de músicos que tocavam para seu deleite, e o nosso obidense Baltazar Gomes Figueira (1604-1674), muito bom pintor de naturezas-mortas, era exímio como instrumentista, sendo por isso reconhecido como virtuoso nos anos de formação em Sevilha. Os exemplos multiplicam-se e basta percorrer o clássico livro Born under Saturn de Rudolf e Margot Wittkower para atestar essa fusão de interesses das artes plásticas e musicais em várias latitudes, épocas e escolas artísticas, desde a Antiguidade ao século xx.

Poder-se-iam assinalar muitos mais exemplos como os casos em apreço, recorrendo tanto a obras de arte existentes como a outras já infelizmente destruídas ou mutiladas, mas cuja memória cripto-artística (tal como na terminologia da História da Arte se denomina a realidade de indicio ou fragmento de um todo já inexistente) tem forçosamente de contar numa base inventarial exaustiva. Só com uma perspectiva global se pode cumprir um objectivo dotado destes pressupostos, e só assim se reforça a necessidade e utilidade desse corpus de iconografia musical - de que continuamos a carecer como projecto interdisciplinar de conjunto - unindo nesse esforço historiadores

\footnotetext{
69 Veja-se a obra de Benvenuto Disertori (Trento 1887 - Milão 1966) que como musicólogo, gravador, e reputado paleógrafo musical - fundou em Cremona o Instituto Cesari de paleografia musical da Universidade de Parma -, transcreveu várias músicas que aparecem representadas em pinturas antigas.
} 
de arte, investigadores de musicologia e de etnomusicologia, antropólogos e historiadores, congregados num esforço de recenseamento sem limites cronológicos ou conceptuais.

\section{Por uma Base de Dados nacional de existências e perdas}

A verdade, porém, é que ainda carecemos dessa Base de Dados exaustiva que documente as existências artístico-patrominiais-musicais (digamos assim), que as situe, que as caracterize, que as estude e identifique com o necessário rigor.

Referimo-nos (como dizia a Prof. Maria Augusta Barbosa) a uma base segura de recenseamento por onde se possa estabelecer - por exemplo - a fidelidade da representação musical em causa numa determinada pintura ou escultura, o modo como o instrumento é referenciado (e, bem ou mal, usado), a que tipo de música corresponde, etc etc. Acrescentaríamos que também a base seguida pelo artista (através da observação de visu, nuns casos, ou inspirando-se, com maior ou menor rigorismo, numa fonte gravada, noutros casos talvez mais vulgares), ou a carga simbólica tributável à integração temática em determinado contexto narrativo, são aspectos fundamentais a considerar.

Eis um caminho fascinante, para o qual a Prof. Maria Augusta Barbosa apontou caminhos e destacou a verdadeira importância da empresa. Continua hoje a ser urgente recriar as bases interdisciplinares que permitam colmatar essa lacuna de bases, reunindo antes de mais a informação múltipla colhida de inúmeros projectos e teses universitárias saídas nos anos recentes e, de seguida, estendendo a verificação identitária de espécimes ao território nacional com âmbito exaustivo, sem esquecer, também, a dimensão criptoartística das perdas. Essa será, aliás, uma das mais consistentes homenagens que a comunidade científica pode prestar à nossa centenária homenageada.

É evidente que a situação demonstra a maior actualidade, até porque existe hoje uma base de conhecimentos de que não dispunha, por exemplo um Mário de Sampayo Ribeiro ou os estudiosos da sua geração nos anos centrais do século passado, alguns deles muitas das vezes atraídos mais pelo pitoresco de uma representação de um cortejo cortesão ou de uma sinfonia de anjos num 
retábulo sacro do que, propriamente, pelo estudo das fidelidades representativas ou das razões iconológicas de uma opção criadora...

Novos equipamentos de importância apareceram entretanto, todos eles dinamizadores de novas pesquisas neste campo.

É imperioso lembrá-los, sem intuitos de exaustividade e sem receio de não referir alguns nesta breve síntese que é, sobretudo, uma homenagem à Prof. Maria Augusta Barbosa, espécie de patrona destas linhas de investigação que começam, finalmente, a ganhar forma autonomizada.

1) Por um lado, a criação do Museu da Música, gerado em 1994 por iniciativa do Instituto dos Museus e da Conservação, com a sua valiosa colecção de instrumentos e, também, de representações artísticas e documentais, com objectivo de salvaguardar, conservar, estudar, valorizar, divulgar e desenvolver o património musicológico, fonográfico e organológico português, tendo em vista o incentivo à qualificação e divulgação da cultura musical portuguesa, associando-se, nessa dimensão, ao esforço de recenseamento iconográfico musical do país. A diretora do Museu, Maria Helena Ferraz Trindade, levou a cabo em 1999 uma exposição muito valiosa de Arte e Música. Iconografia Musical na Pintura do Século $x v$ ao Século $x x$, que alargou expectativas de abordagem ao cruzar tempos distintos e olhares plurais na representação musical..$^{70}$

2) Em 2000, o Núcleo de Iconografia Musical do Centro de Estudos de Sociologia e Estética Musical (CESEM) veio estruturar estudos de gabinete de âmbito iconográfico sobre a música portuguesa através das artes, dando corpo ao projeto Images of Music - a Cultural Heritage, saído em 2006.

3) Por outro lado, desenvolveram-se de maneira significativa os estudos universitários em departamentos especializados das Universidades (Coimbra, FCSH de Lisboa, Aveiro e Évora), com a génese de uma série de dissertações, orientadas por investigadores de renome no campo da Musicologia, que nasceram, foram devidamente apoiadas e defendidas no seio dos Departamentos de Ciências Musicais dessas estruturas de ensino. Dispomos hoje de uma série de teses de pós-graduação dedicadas a esse propósito. ${ }^{71}$

\footnotetext{
70 M. H. F. Trindade (coord.) 1999

71 Cf. por exemplo, sem intuitos de exaustividade, e entre as primeiras, a tese de M. do A. Monteiro 1992 e, entre as mais recentes, S. M. da S. Duarte 2011.
} 
4) Enfim, é de destacar também a bem sucedida candidatura do Fado a Património Imaterial da Humanidade, desenvolvendo a propósito um levantamento pioneiro da guitarra portuguesa e o modo como tem sido representada no campo das artes, portuguesas e não só. ${ }^{72}$

Todos estes equipamentos, esforços e sinergias começam a pôr ênfase na importância dos estudos musicais à luz da sua representação no terreno da arte portuguesa - depois de se constatar quão original se revelava o património artístico português nesse aspecto particular em termos de existências, das mais eruditas às mais populares -, não já numa mera dimensão localizada mas com a consciência de que importa integrar esse interesse numa visão globalizadora e pluri-disciplinar.

\section{Um status quaestionis dos estudos artístico-musicais convergentes}

Terminamos com um breve panorama sobre a importância destes estudos, ainda tão embrionários no tempo de Mário de Sampayo Ribeiro e que, com a Democracia portuguesa após 1974 , tenderam a reforçar o seu papel e a ter possibilidade de crescerem, desde um estado muito residual de interesses até se constituírem terreno de eleição.

Panorama de certa marginalidade era, de facto, o tempo e as condições em que Sampayo Ribeiro pôde olhar para os Primitivos Portugueses, sem que do seu esforço se seguisse uma natural continuação de interesses. Já em 1976 o assunto estava vivo, no afã de uma situalção política que era de euforia na busca de saberes e no reforço de uma identidade cultural a reconstruir, e ganhara-se consciência tal da importância dos estudos artístico-musicais na área patrimonial, que a Direcção Geral do Património Cultural da Secretaria de Estado da Cultura iniciava, com Humberto d'Ávila como seu dinamizador maior, um projecto a que se chamou Levantamento da Iconografia Musical em Portugal e Registo de Instrumentos, que teve resultados pontuais muito interessantes. A base de dados cobriu sobretudo os museus estatais, ainda

\footnotetext{
72 Cf., por exemplo, S. Pereira 2009. Da mesma autora, directora do Museu do Fado e doutoranda em História da Arte pela Faculdade de Letras de Lisboa, cf. 2005.
} 
que o projecto não tivesse possibilidade prática de se estender ao grosso da paisagem nacional, como era sua intenção inicial. ${ }^{73}$

A iniciativa teria, de certa maneira, continuidade através do Instituto Português do Património Cultural, com direcção de João Palma Ferreira, num esforço para inventariar a iconografia musical portuguesa, que teve no Departamento de Ciências Sociais da FCSH um esforço de campo significativo ${ }^{74}$, com resultados em fichagens e, também, com ensaios de síntese, como no campo da iluminura medieval e renascentista ${ }^{75}$, ou no das representações de instrumentos nos Presépios barrocos de madeira e terracota, entre outros. ${ }^{76}$ Foi com o ensaio de Luís Henrique, Instrumentos Musicais, saído em 1988 e várias vezes reeditado ${ }^{77}$, que os estudiosos passaram a contar com uma base credível de análise e cotejo de representações.

A grande exposição coordenada por Natália Correia Guedes no Mosteiro de São Vicente de Fora em 1994, Encontro de culturas: oito séculos de missionação portuguesa, teve o especial interesse de alargar o registo das representações musicais, e a sua presença instrumental objectiva, para os espaços da lusofonia, integrando testemunhos dos espaços do antigo império português. ${ }^{78}$ Foi, nessa perspetiva, um virar de página de interesses integrados e robustecidos.

O empenho maior dos estudiosos tem enfocado com maior poder de observação, sempre, o campo da pintura dos séculos xv e xvi e é fácil perceber-se

73 Infelizmente, o processo foi interrompido, dele restando, sobretudo, os materiais de levantamento relativos aos museus nacionais.

74 De resultados parcelares, este pré-inventário produziu, p. ex., um conjunto de estudos reunidos no $\mathrm{n}^{\circ} 52$ do Boletim da Associação Portuguesa de Educação Musical, $\mathrm{n}^{\circ}$ 52, Janeiro-Março de 1987.

75 B. A. Gomes e M. J. Borges 1987.

76 M. A. Latino 1987.

77 L. Henrique 1988.

78 N. C. Guedes (coord.) 1994. Sobre a participação d Maria Augusta Barbosa na recolha, selecção, inventariação e tratamento das peças que constituíram a Secção de Música no contexto da missionação em todas as parte do antigo Império português, em que se percorreu o país de Norte a Sul, e se contactaram entidades e coleccionadores de instrumentos e documentos ligados ao tema, quer nacionais, quer internacionais, desde os museus, arquivos, centros de pesquisa, casas missionárias, etc, até a colecções do Vaticano ou outras, há ainda um testemunho a dar por um dos autores (M.A.A.) que acompanhou durante dois anos a sua Mestre Maria Augusta na fase preparatória da montagem da referida exposição, tendo em sua posse os materiais recolhidos destinados a um trabalho de maior fôlego em forma de homenagem para o conhecimento de mais esta importantíssima actividade de Maria Augusta Barbosa em prol da Arte da Música, e que, por motivos de saúde, foi impedida de terminar o texto que sairia no catálogo. 
porquê. As representações temáticas da Adoração dos Pastores e da Assunção da Virgem, muito comuns no contexto narrativo dos retábulos das igrejas e mosteiros durante o século xvi, foram especialmente adequadas para a integração de um sem-número de instrumentos musicais a fim de dar credibilidade maior aos concertos angelicais, entendidos como uma espécie de música celestial ao vivo, como Mário de Sampayo Ribeiro de há muito demonstrou, estudando algumas pinturas renascentistas com essas temáticas. ${ }^{79}$ Para este musicólogo, que abriu um campo de análise comum à História da Arte e à Musicologia dotado de futuro, os instrumentos que os pintores representavam só em certos casos eram fidedignos - e existem imensos casos desse rigorismo seguido e cumprido (que devem ser explicados à luz da encomenda), pois refletiam conhecimento direto das suas propriedades), havendo embora um sem-número de obras com simplificações na representação dos instrumentos, com incorreções de uso, etc etc. O relatório de Sampayo Ribeiro foi importantíssimo por nos dar a ver modos distintos de representação a revelar atitudes distintas por parte dos encomendantes e dos públicos.

É de destacar também, entre outros momentos de construção de um caminho de re-conbecimento do Património artístico-musical, o trabalho que em 1962 se realizou no Museu Nacional de Arte Antiga aquando da reunião da Comissão Internacional do ICOM, através de um certame sobre Temas Musicais nas Obras de Arte do Museu Nacional de Arte Antiga. ${ }^{80}$ Seguiram-se o ensaio incontornável do antropólogo Ernesto Veiga de Oliveira sobre instrumentos musicais portugueses ${ }^{81} \mathrm{e}$, numa dimensão mais pomntual de 'estudo de caso', o trabalho colectivo coordenado pelo historiador de arte Prof. Jorge Henrique Pais da Silva sobre uma obra célebre da pintura 'manuelina', o retábulo de Santa Auta (M.N.A.A.) ${ }^{82}$, com exame das representações de instrumentos e grupos musicais devida e exemplarmente tratados. ${ }^{83}$ No campo da iluminura dos séculos xv e xvı, há numerosa bibliografia dedicada ao canto

\footnotetext{
79 M. de S. Ribeiro 1943.

80 Cat. da exp. Temas Musicais nas Obras de Arte do Museu Nacional de Arte Antiga, MNAA, 1962.

81 E. V. de Oliveira 1966 ( $2^{\text {a }}$ ed. revista, 1982).

82 J. H. P. da Silva (coord.) 1972.

83 Manuel Morais e Sérgio Guimarães de Andrade ocuparam-se dessas temáticas específicas no citado estudo coordenado por Jorge Henrique Pais da Silva, op. cit., pp. 44-50.
} 
litúrgico, à polifonia, aos repertórios musicais portugueses, etc, que se abre também à leitura das representações de instrumentos e práticas de música, como é o caso dos estudos de José Maria Pedrosa Cardoso ${ }^{84}$, entre outros.

Dito isto, pensamos que o terreno está hoje sedimentado, em interesses multiplicados e metodologias experimentadas, para se estruturar a almejada Base de Dados exaustiva de iconografia musical portuguesa, base de estudo fundamental e inadiável, para cuja realização muito pugnou a Prof. Maria Augusta Barbosa.

Que esse corpus não pode ser limitada tão-só às pretensas obras-primas, mas à totalidade do património sobrevivente, é mais que certo: basta ver-se a quantidade e interesse das representações artística não eruditas (na talha dourada do Barroco beirão e transmontano, por exemplo), para se constatar que só com um cotejo alargado podem fazer sentido os dados cotejáveis.

Que a sua extensão no tempo e no espaço permite aclarar práticas no terreno, usos e gostos, perdurações memoriais e influências externas, disso não existe qualquer dúvida: basta ver-se como a presença de certos instrumentos em determinadas regiões se explica por esse destaque estatutário, digamos assim, da representação artística.

Que o interesse é múltiplo, pois ajuda a ver o grau de realismo dos artistas, também não resta qualquer dúvida, responsabilizando mais e melhor os historiadores (da arte e não só) por esse esforço colectivo.

Enfim, que esse enfoque inventarial tem de integrar a experiência lusófona, os instrumentos representados e as formas etnomusicais e de convivialidade com o outro, e o modo como tal se processou e reflectiu através das artes (o marfim, o bronze relevado, etc), eis uma dimensão fundamental a aduzir em reforço a esta Base de Dados.

\section{Bibliografia}

Cardoso, José Maria Pedrosa (2006), O Canto da Paixão nos séculos XVI e XVII: A Singularidade Portuguesa. Coimbra.

\footnotetext{
84 J. M. P. Cardoso 2006.
} 
Duarte, Sónia Maria da Silva (2011), O contributo da iconografia musical na pintura quinhentista portuguesa, luso-flamenga e flamenga em Portugal, para o reconhecimento das práticas musicais da época: fontes e modelos utilizados nas oficinas de pintura, Mestrado em Ciências Musicais, Faculdade de Ciências Sociais e Humanas. Lisboa.

Fabiani, Enzo (1993), "Cuadros, partituras e instrumentos. Música angelica», revista Amadeus, $\mathrm{n}^{\circ}$ 8, 1993, pp. 47-49.

Gomes, Bernardo Azevedo e Borges, Maria José (1987), «As representações musicais nos códices da Leitura Nova: elementos para o estudo da prática musical e seu contexto ideológico na Corte portuguesa de Quinhentos", VEncontro Nacional de Musicologia, Actas. Lisboa.

Guedes, Natália Correia (1994) (coord.), Encontro de culturas: oito séculos de missionação portuguesa, Mosteiro de S. Vicente de Fora. Lisboa.

Henrique, Luís (1988), Instrumentos Musicais. Lisboa.

Latino, Maria Adriana (1987), «A representação de instrumentos musicais em alguns Presépios portugueses do século xvIII", Boletim da Associação Portuguesa de Educação Musical, $\mathrm{n}^{\circ}$ 52, pp. 62-65.

Meco, José (1989), O Azulejo em Portugal. Lisboa.

Monteiro, Maria do Amparo (1992), A Iconografia musical na Cidade de Coimbra, Mestrado em Ciências Musicais, Faculdade de Letras da Universidade de Coimbra.

Nery, Rui Vieira (1991), The Music Manuscripts in ther Library of King D. João IV of Portugal (1604-1650): a study of Iberian Reportoire in the Sixteenth and Seventeenth centuries, 2 vols. Austin.

Oliveira, Ernesto Veiga de (1966), Instrumentos Musicais Populares Portugueses. Lisboa.

Pereira, Sara (2005) O Fado por Stuart Carvalhais, EGEAC/Museu do Fado. Lisboa.

Pereira, Sara (2009), "Ecos do Silêncio: Para um Estudo Iconológico do Fado", in Actas do Encontro Aprendizes de Feiticeiro, ed. Instituto de História da Arte, Universidade de Lisboa.

Ribeiro, Mário de Sampayo (1943), Aspectos musicais da Exposição de Os Primitivos Portugueses (1450-1550), Centro de Estudos de Arte e Museologia do Instituto para a Alta Cultura, Lisboa.

Serrão, Vítor (2001), «Le panneau de Vasco Fernandes, dit Grão Vasco, dans l'église de Santa Maria de Porco (Guarda)", Revue de l'Art, Paris, 2001, n 4, pp. 57-70.

Serrão, Vítor(2008), O Fresco Maneirista no Paço de Vila Viçosa, Parnaso dos Duques de Bragança. Lisboa.

Silva, Jorge Henrique Pais da (coord.) (1972), Retábulo de Santa Auta. Estudo de Investigação, Centro de Estudos de Arte e Museologia do Instituto para a Alta Cultura. Lisboa.

Teixeira, José (1983), O Paço Ducal de Vila Viçosa. Lisboa.

Trindade, Maria Helena Ferraz (coord.) (1999), Arte e Música. Iconografia Musical na Pintura do Século $x V$ ao Século $x x$. Lisboa. 

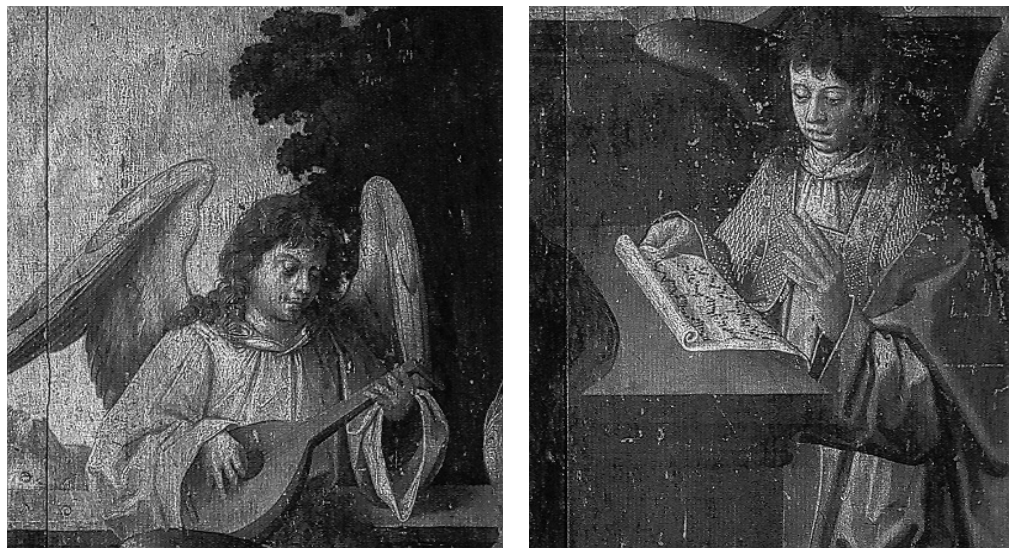

1 e 2 - Anjos com instrumento e pauta musical, pormenores de $A$ Virgem, o Menino e Anjos de Vasco Fernandes na igreja de Aldeia Viçosa (Guarda), c. 1530.

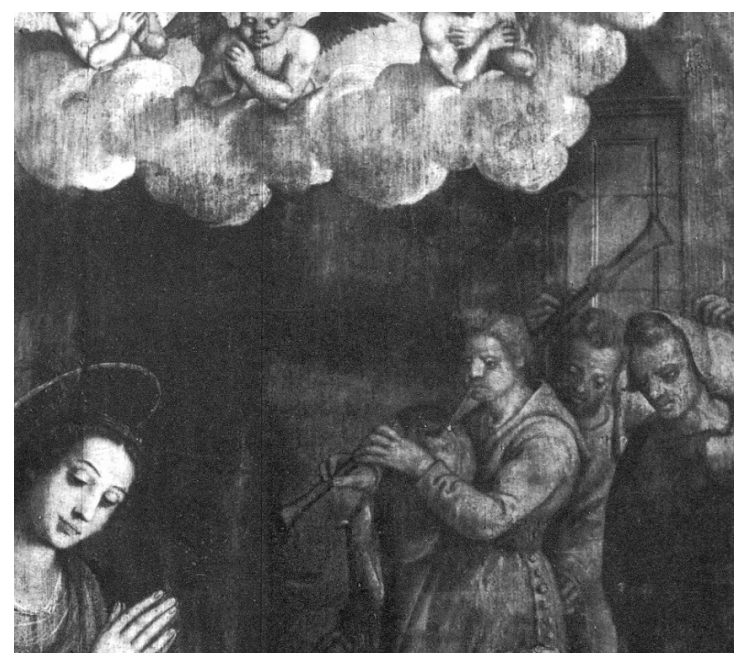

3 - Pastor com gaita de foles, pormenor da Adoração dos Pastores de Diogo Teixeira e António da Costa na igreja da Misericórdia de Alcochete, 1586-1588. 


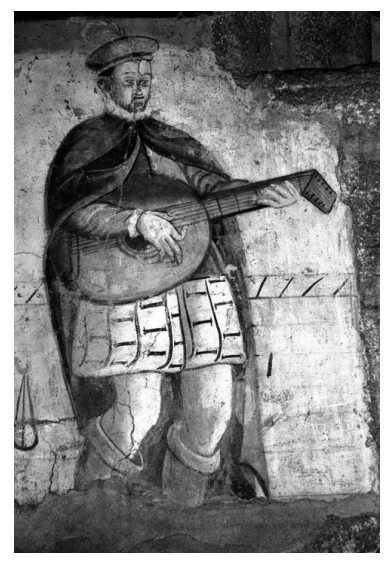

4 - Ingénua representação de jogral num fresco anónimo

do fim do século xvı na igreja de Veigas (Bragança).

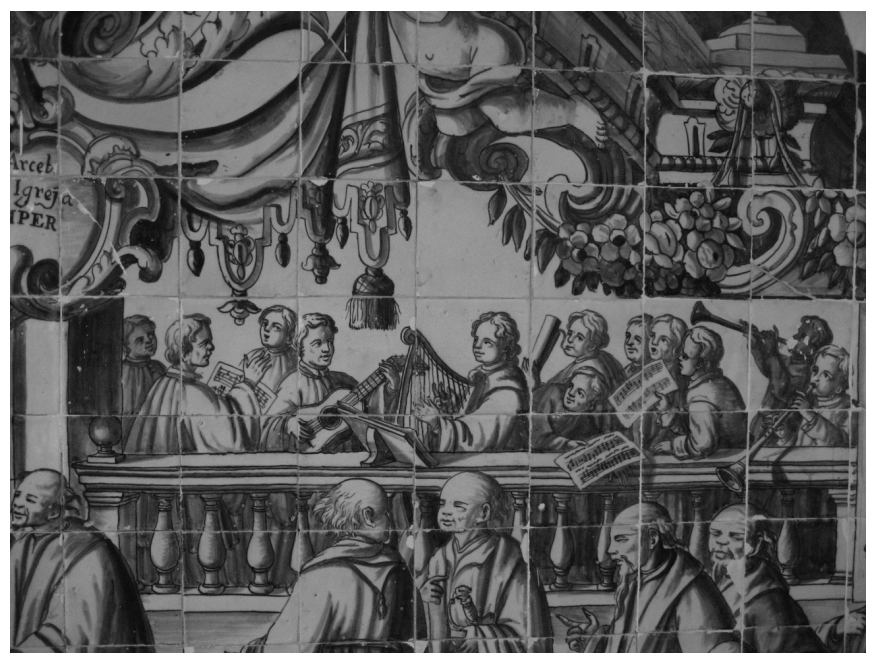

5 - Pormenor dos azulejos com a Vida de D. Frei Aleixo de Meneses no claustro do Convento de Nossa Senhora da Graça de Torres Vedras, pelo Mestrre P.M.P., c. 1720. 


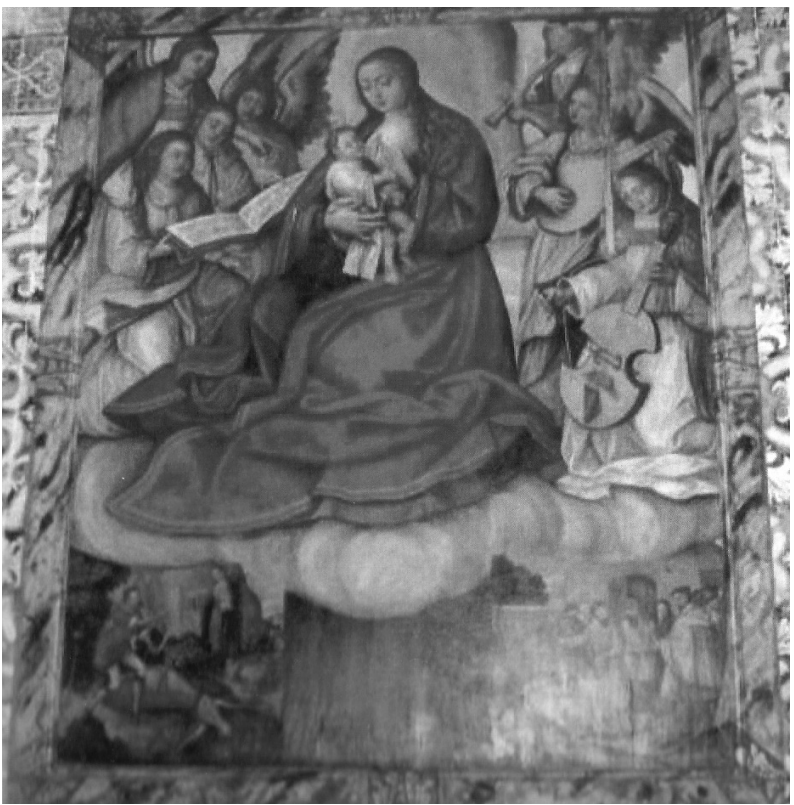

6 - Pormenor do Milagre de Nossa Senhora de Brotas, pintura renascentista de oficina eborense de meado do século xvi, com instrumentos e temas musicais. Mora, Santuário de Nossa Senhora de Brotas.

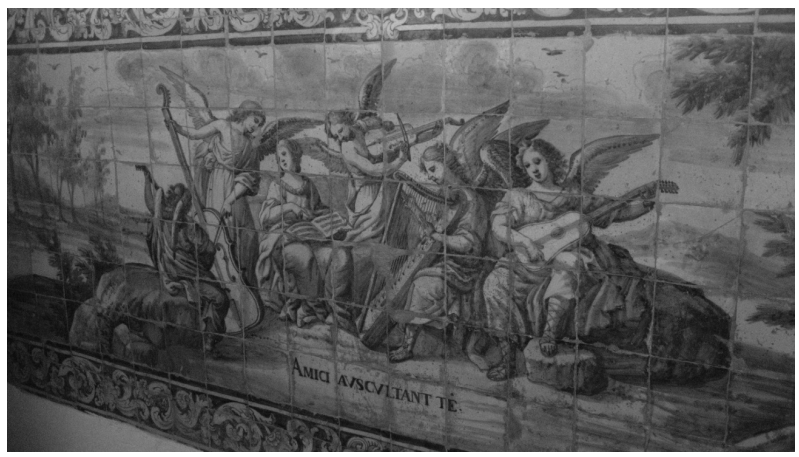

7 - Azulejo com passo do Cântico dos Cânticos, por António de Oliveira Bernardes, no antigo Convento de São Paulo da Serra d'Ossa, no Redondo, cerca de 1710. 


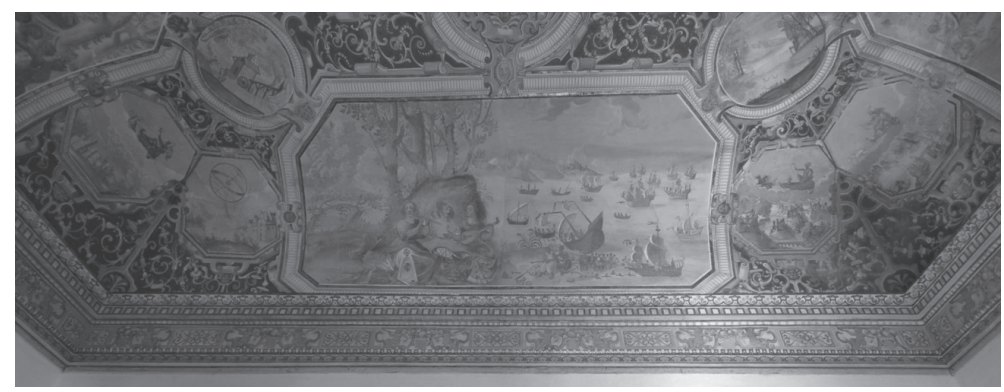

8 - Pormenor de um dos tectos da Sala de Música do Duque de Bragança D. João II

(futuro D. João IV) no Paço Ducal de Vila Viçosa, autor desconhecido, c. 1635.

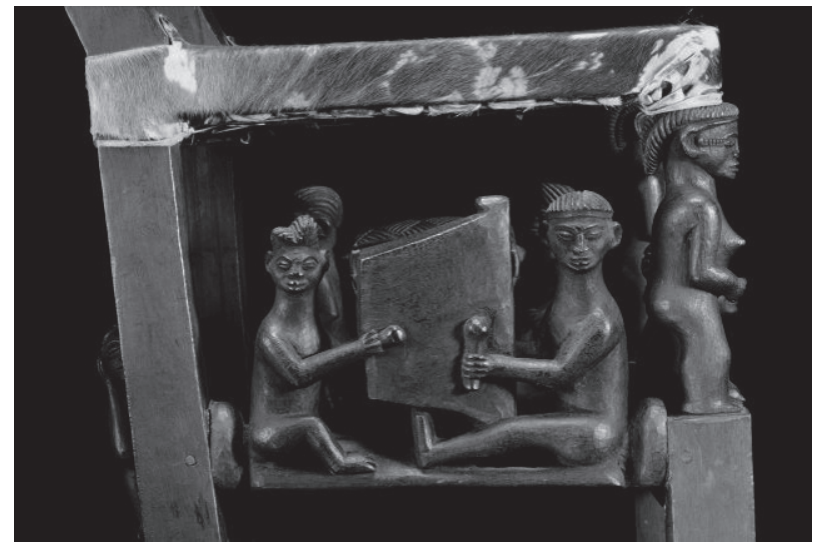

9 - Cadeira de soba: «lateralmente, dois músicos sentados tocam um grande tambor de fenda trapezoidal (cinguvu) com baquetas" proveniente dos Missionários do Espírito Santo, Coimbra, ANT.D.84.1.129. 